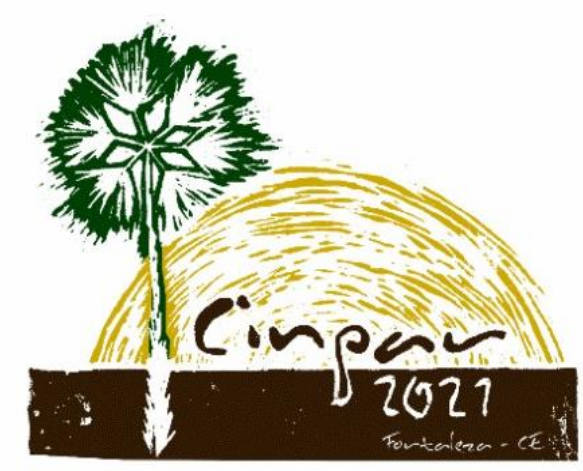

XVII Congresso Internacional sobre Patologia e

Reabilitação das Construções

XVII Congreso Internacional sobre Patología y Rehabilitación de las Construcciones

XVII International Conference on Pathology and Constructions Rehabilitation

FORTALEZA (Brasil), 3 a 5 de junho de 2021

https://doi.org/10.4322/CINPAR.2021.133

\title{
INVESTIGAÇÃO DAS MANIFESTAÇÕES PATOLÓGICAS NO SISTEMA CONSTRUTIVO LIGHT STEEL FRAMING: UM ESTUDO DE CASO
}

\section{INVESTIGATION OF PATHOLOGICAL MANIFESTATIONS IN THE LIGHT STEEL FRAMING BUILDING SYSTEM: A CASE STUDY}

\author{
Lucas Menezes de Farias ${ }^{1}$, Jefferson Luiz Alves Marinho ${ }^{2}$
}

${ }^{1}$ Universidade Regional do Cariri - URCA, Juazeiro do Norte - CE, Brasil, lucasmenezes547@gmail.com 2 Universidade Regional do Cariri - CE, Juazeiro do Norte - CE, Brasil, jeff.marinho@urca.br

\begin{abstract}
Resumo: A indústria da Construção no Brasil ainda é caracterizada pela utilização de sistemas construtivos predominantemente artesanais, tendo como característica a baixa produtividade e o grande desperdício de materiais. Nesse contexto, a fim de reduzir perdas e atender à crescente deman da do mercado, a busca por métodos construtivos alternativos é uma das questões centrais na construção civil, no âmbito econômico, sustentável e social. Em função disso, a flexibilidade e agilidade do uso do sistema Light Steel Frame (LSF) está sendo uma grande vantagem quando comparado aos métodos tradicionais da construção civil, pois sua aplicabilidade é feita através de materiais sustentáveis diminuindo a geração de resíduos, obtendo assim o menor impacto possível no meio ambiente e a diminuição do desperdício de materiais. Nesse âmbito, o objetivo deste trabalho foi realizar o levantamento das possíveis manifestações patológicas no sistema construtivo LSF na cidade de Juazeiro do Norte/CE, analisando sua implantação na referida cidade. Para a realização deste trabalho foi utilizado como método a pesquisa bibliográfica, além de incluir a pesquisa de campo em edificações construídas com o sistema LSF. Destaca-se como resultado que a única manifestação patológica encontrada e relacionada pelo sistema LSF foi a existência de fissuras nas juntas de dilatação dos painéis de vedação. Dessa forma, com base na agregação de valores sustentáveis e benéficos, a aplicação do LSF tem muito a contribuir no setor da construção civil, pois apresenta inúmeras vantagens com construções cada vez mais rápidas, economicamente viáveis, maior garantia das especificações e ambientalmente menos impactantes.
\end{abstract}

Palavras-chave: Light Steel Framing. Inovação Tecnológica. Racionalização. Construção Sustentável. Manifestações Patológicas.

Abstract: The construction industry in Brazil is still characterized by the use of predominantly handmade construction systems, characterized by low productivity and great waste of materials. In this context, in order to reduce losses and meet the growing market demand, the search for alternative construction methods is one of the central issues in civil construction, in the economic, sustainable and social spheres. Because of this, the flexibility and agility of the Light Steel Frame (LSF) system is being a great advantage when compared to traditional methods of construction, because its applicability is made through sustainable materials reducing the generation of waste, thus obtaining the lowest possible impact on the environment and reducing the waste of materials. In this context, the objective of this work was to conduct a survey of possible pathological manifestations in the LSF building system in the city of Juazeiro do Norte/CE, analyzing its implementation in the city. To carry out this work, the bibliographical research was used as a method, besides including field research in buildings built with the LSF system. As a result, the only pathological manifestation found and related to the SPS system was the existence of cracks in the expansion joints of the sealing panels. Thus, based on the aggregation of sustainable and beneficial values, the application of LSF has much to contribute in the construction 
sector, as it presents numerous advantages with increasingly faster constructions, economically feasible, greater guarantee of specifications and environmentally less impactful.

Keywords: Light Steel Framing. Technological Innovation. Rationalization. Sustainable Construction. Pathological Manifestations.

\section{Introdução}

Marinho (2017) afirma que a incorporação de práticas de sustentabilidade tem sido uma tendência crescente na indústria da construção civil, cujos profissionais e empresas já estão mudando a forma de produzir e gerir os empreendimentos. De acordo com o autor supracitado, preocupações com a utilização racional de energia e de matérias-primas, com a menor geração de resíduos, com a preservação do ambiente natural e com a melhoria da qualidade do ambiente construído, têm induzido as organizações a incorporarem novas técnicas construtivas.

O crescimento acelerado da construção civil e a busca constante por inovação tecnológica tem tornado o mercado cada vez mais exigente, buscando sempre qualidade e menor custo. Por outro lado, isso tem colocado em dúvidas o desempenho das edificações e chamado a atenção de pesquisadores para investigar as diversas manifestações patológicas que tem afetado seriamente as edificações. Para os autores supracitados, os problemas provenientes de manifestações patológicas vão desde pequenos danos até o comprometimento da segurança das edificações, podendo culminar com o colapso das estruturas (MARINHO e MESQUITA, 2020).

Estruturas de forma geral, sejam em concreto armado, metálicas, madeira ou outros materiais, possuem em comum o fato de resistirem a esforços mecânicos. Contudo, além de resistir a essas solicitações, sofrem também a influência de intemperismos, variações térmicas e higroscópicas, dentre outras, que ao longo do tempo, a depender do tipo empregado, resultará em um determinado grau de deterioração, seja conforme o tempo de vida útil da edificação, ou precocemente devido à fatores patológicos (TARGINO et al., 2020). Para os autores, é possível observar uma tendência crescente na ocorrência de manifestações patológicas ligadas a erros executivos, falta de capacitação para incorporação de novos processos e tecnologias não consolidadas.

Schafirstein e D'ávila (2018) declaram que as manifestações patológicas se configuram como um problema antigo de grande importância, tanto do posto de vista econômico quanto do ponto de vista social. Para os autores supracitados, há uma série de fatores que interferem na vida útil de um sistema construído e que ocorrem durante todas as suas fases, sendo elas: o projeto, a execução e a posterior manutenção. Em se tendo tudo em conformidade às especificações e aos parâmetros testados, há uma probabilidade real de que a vida desse sistema seja bastante duradoura.

Santos et al. (2018) corroboram com esse entendimento afirmando que as condições que envolvem as variáveis ambientais específicas do meio em que cada edificação está inserida, as condições de uso, as características construtivas, a frequência de manutenção, entre outros fatores, favorece o surgimento de mecanismos de degradação bastante peculiares.

Dito isso, o conhecimento e o tratamento das falhas de uma edificação colaboram com o aumento de sua vida útil, além é claro, de trazer notável segurança aos usuários e contribuir para melhorar a estética da cidade (ARAUJO e SALES, 2020).

Em função disso, a indústria da construção civil tem buscado sistemas construtivos mais eficientes no intuito de aumentar a produtividade, diminuir o desperdício e atender a uma demanda crescente. Entre as opções, o sistema estrutural de aço tem se destacado, pois é um material resistente e que atende às solicitações de uma construção ágil, limpa, sustentável e de qualidade.

Nesse sentido, o sistema construtivo Steel Frame, também conhecido como construção LSF (Light Steel Framing) ou estrutura em aço, é reconhecido internacionalmente para definir o material construtivo que utiliza o aço galvanizado como principal elemento estrutural, gerando edificações de baixo peso. Com isso, pode-se entender que o aço será utilizado na construção no lugar do concreto, fazendo com que a edificação em si tenha o seu peso diminuído de forma tão significativa que suas fundações também são forçadamente menores (TEIXEIRA e SIMPLICIO, 2018). 
Na grande maioria dos casos, a escolha pelo LSF é feita também devido à sua grande capacidade de resolver diferentes exigências de premissas e programas cada vez mais variáveis nos projetos atuais. A versatilidade e flexibilidade do material e de suas articulações referem-se à grandes capacidades de adaptação em relação a inúmeras tipologias, escolhas de acabamento, resistência a climas adversos, abalos sísmicos, riscos de incêndios e também distintas atemporalidades.

Outra característica que faz dele algo cada vez mais popular na atualidade é a sua ótima relação com a questão da sustentabilidade, grande tendência em várias esferas da vida contemporânea e um fator cada vez mais discutido e levado em conta nas premissas de projeto. Ele é ecologicamente correto na medida em que é pouco agressivo ao ambiente; a utilização de água é praticamente nula durante o processo de execução e não há grandes desperdícios em relação a nenhuma outra matéria-prima da natureza. Sendo um sistema construtivo a seco, a água empregada é limitada à fundação da edificação e ao assentamento de revestimentos cerâmicos (CHAN e FONTANINI, 2017).

Além disso, a especialização da mão de obra, em conjunto com a montagem em série, diminui consideravelmente o desperdício de matéria prima. Com isso, um dos grandes impactos ambientais causados pela construção civil é reduzido. Deste modo, o LSF apresenta eficiência de materiais, uma das características da sustentabilidade (DEGANI, 2017).

Dito isso, este trabalho justifica-se, primeiramente, em virtude do sistema construtivo LSF gerar impactos no custo e tempo de execução da construção de forma que, mesmo que o custo direto com estes insumos seja maior por se tratarem de tecnologias pouco difundidas, os custos pela diminuição do tempo de obra e fatores administrativos podem tornar esta tecnologia viável. Nesse âmbito, o tema a ser estudado é relevante na minimização dos impactos ambientais, sociais e econômicos na construção civil. Posto isto, a originalidade do presente trabalho reside em realizar o levantamento das possíveis manifestações patológicas no sistema construtivo LSF na cidade de Juazeiro do Norte/CE, analisando sua implantação na referida cidade.

\section{Material e Métodos}

Nesta seção será apresentado o método empregado aplicado aos estudos realizados (Fluxograma 1). Para tanto foi subdividido em cinco etapas essenciais: i) Revisão bibliográfica; ii) Visitas in loco às edificações construídas no sistema em LSF; iii) Coleta de dados através de entrevistas; iv) Classificação e quantificação das possíveis manifestações patológicas encontradas no sistema LSF; v) Avaliação dos possíveis tipos de manifestações patológicas encontradas cuja as especificidades serão detalhadas posteriormente.

Figura 1 - Estrutura do programa metodológico

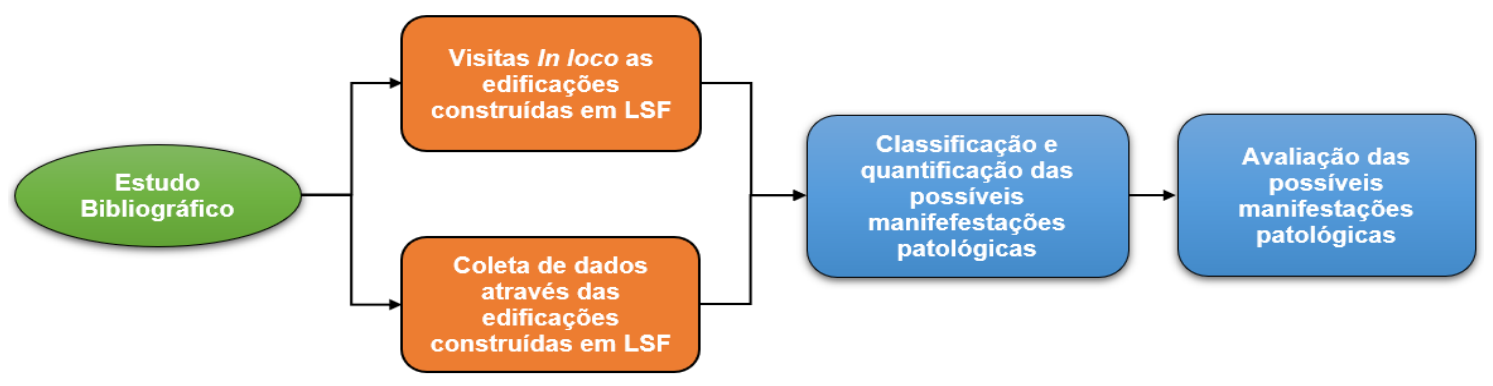

Fonte: Autores (2021)

Conforme a Figura 1, inicialmente foi realizado uma revisão bibliográfica de trabalhos acadêmicos, cujo o tema pudesse servir como base de conhecimento sobre o assunto na procura de informações qualificadas. As consultas aconteceram em pesquisas de artigos publicados recentemente em eventos científicos, dissertações e livros relacionados aos temas de: patologias, manifestações patológicas, custos para as construções em LSF, vantagens e desvantagens do sistema construtivo LSF, financiamentos bancários de obras construídas com LSF e minimização dos impactos ambientais na implantação do LSF, além de consultas em revistas e Normas Técnicas. Nas etapas posteriores, foram realizadas visitas técnicas nas obras construídas no sistema construtivo LSF na área de estudo da cidade de Juazeiro do Norte/CE, que está descrita na seção logo abaixo. Através dessas visitas foram coletados 
dados, sobretudo a respeito dos seguintes tópicos sobre o LSF: quantificação de obras construídas na área de estudo juntamente com sua vida útil, incidência de manifestações patológicas, dificuldades de implantação do LSF na região do Cariri, vantagens e desvantagens, financiamento habitacional, relação custo/benefício das edificações, sustentabilidade, entre outros temas relevantes acerca do LSF para a elaboração do trabalho.

\section{1 Área de estudo}

O município de Juazeiro do Norte-CE, situado no Sul do estado do Ceará, distante $491 \mathrm{~km}$ da capital Fortaleza e pertencente à Região Metropolitana do Cariri (RMC) tem uma população estimada em 276.264 habitantes, distribuídos em uma área de $258,788 \mathrm{Km}^{2}$, no qual, aproximadamente $96 \%$ residem em zona urbana (IBGE, 2020). Está localizado na região Nordeste ao Sul do estado do Ceará, precisamente entre $7^{\circ} 12^{\prime} 47^{\prime \prime}$ de latitude Sul (S) e $39^{\circ} 18^{\prime} 55^{\prime \prime}$ de longitude Oeste (W), e limita-se ao Norte com o município de Caririaçu, ao Sul com o município de Crato, Barbalha e Missão Velha, ao leste com o município de Missão velha e Caririaçu e ao Oeste com o município de Crato (IBGE/IPECE, 2017). A Figura 1 abaixo apresenta o mapa de localização da área de estudo, precisamente situada entre $7^{\circ} 15^{\prime}$ 57.53" de latitude Sul (S) e 39 18' 30.32" de longitude Oeste (W).

\section{Figura 1 - Mapa de localização da região de estudo}

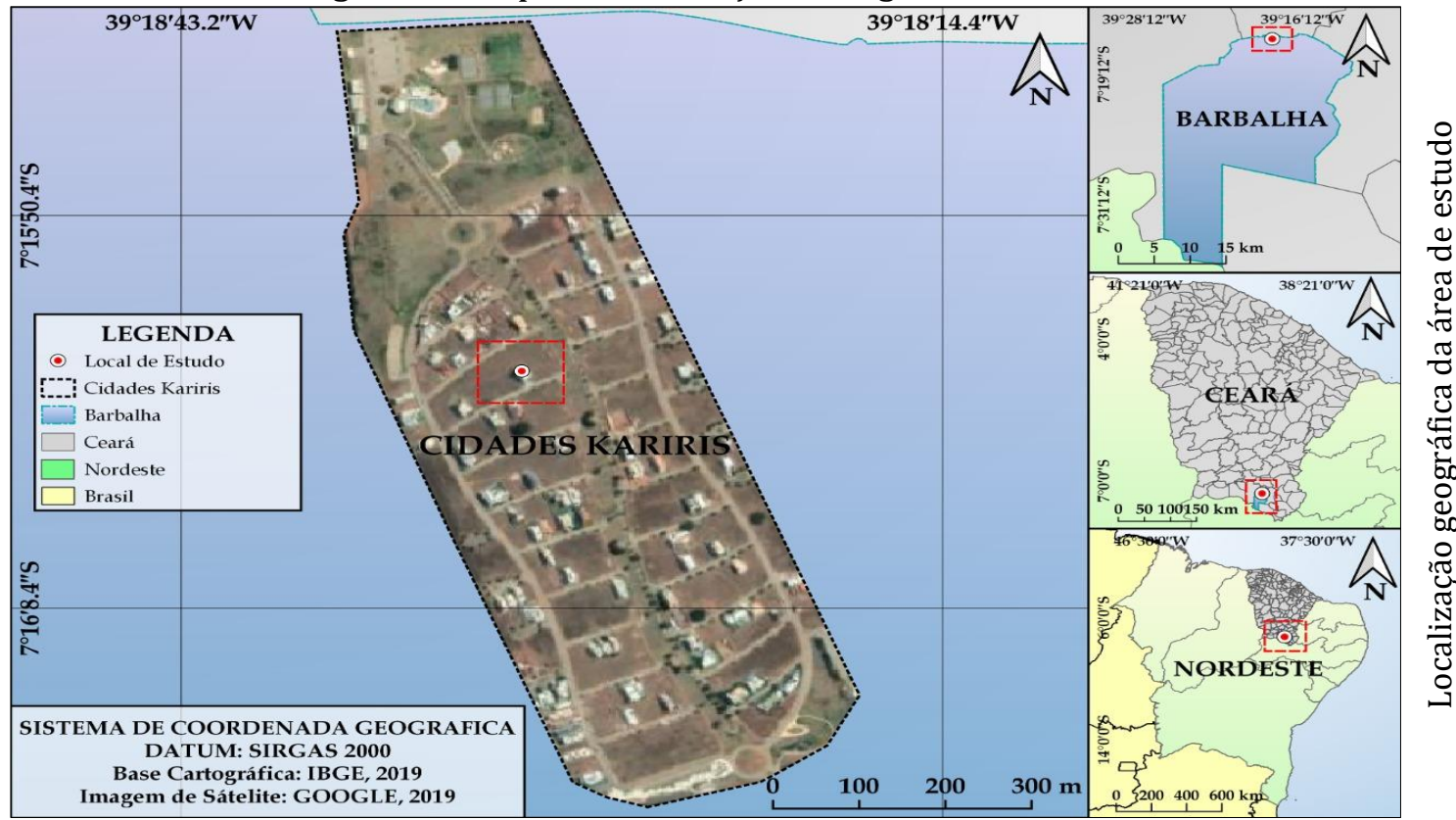

Fonte: Autores (2021)

\section{Resultados e Discussão}

Em relação à área de estudo existem três edificações construídas através do LSF, sendo que duas delas são residenciais com quatro anos de concluídas, e a outra é uma edificação comercial, com tem três anos de concluída. Vale destacar, ainda, que no referido local de estudo existe uma construção em andamento que também utiliza o sistema em LSF. Para a classificação das manifestações patológicas encontradas nas edificações que estavam finalizadas, foram utilizadas as informações oriundas de visitas técnicas e obtidas através das entrevistas realizadas. Vale enfatizar que as entrevistas foram realizadas com o engenheiro responsável pelas construções das edificações em LSF na área de estudo.

Com base nas visitas técnicas realizadas e analisando o quantitativo de quatro edificações construídas em LSF, a única manifestação patológica encontrada em uma das edificações foi a existência de fissuras nas juntas de dilatação que une os painéis de vedação. As causas estão associadas às movimentações térmicas e/ou dilatações, tanto da estrutura do LSF como da placa cimentícia. Vale destacar que essas fissuras comprometem a estanqueidade dessa região estrutural, podendo haver infiltrações.

Vale ressaltar ainda que nos casos em que as fissuras apresentaram danos aparentemente só estéticos, cabe uma análise mais aprofundada uma vez que podem se tornar anomalias estruturais. Por isso, deve 
ser estudado e armazenado em bancos de dados para facilitar ao longo do tempo a resolução de problemas de manifestações patológicas, além de prevenir futuros danos que comprometam a segurança dos seus ocupantes e do imóvel, e consequentemente ocasione também sua desvalorização imobiliária.

A edificação na qual continha essa manifestação patológica supracitada tem quatro anos de concluída. Nesse viés, a obrigação que todo construtor tem, por lei, é de proporcionar quanto à estabilidade e solidez uma garantia mínima de 5 anos, de acordo com Código Civil (Art. 618). Destaca-se ainda que as fissuras foram as únicas manifestações patológicas que ocorreram no sistema construtivo LSF das edificações construídas da área de estudo. Com a progressividade das fissuras, o resultado ao longo dos anos pode ser o aparecimento de infiltrações. A infiltração que pode ser iniciada com uma microfissura, pode acarretar uma infiltração localizada, e se não for tratada devidamente, pode ocasionar sérios problemas em todo o sistema construtivo.

Handa (2019) realizou um estudo em Campinas/SP sobre a identificação das principais Manifestações Patológicas em Fachadas em chapas delgadas estruturadas em LSF, e identificou que as principais manifestações patológicas nos seis estudos de casos realizados foram: fissuras e trincas, infiltração, desplacamento, falha nas interfaces, falha nas juntas, falha na ancoragem, oxidação e corrosão. Para a autora, apesar da existência de outras manifestações patológicas ficou evidente que as fissuras estão entre as maiores vilãs nas edificações utilizando o sistema LSF.

Zuehl (2019) fez a análise das Manifestações Patológicas em estruturas de aço, e concluiu que as fissuras também estavam entre as manifestações patológicas mais recorrentes no LSF. Segundo a autora, as principais causas das manifestações patológicas referentes às edificações estudadas estão relacionadas à concepção inadequada dos projetos, irregularidades na execução e uso incorreto de materiais.

Além de estudar e identificar a aparição das manifestações patológicas que afetam a vida útil do LSF, é essencial entender que a realização de manutenções periódicas nas edificações contribuem para o bom desempenho e efetivamente garantem a vida útil da edificação. Nesse âmbito, Villanueva (2015) defende que a falta de uma cultura de prevenção em nosso país é clara quando observa-se que que a maioria dos usuários dos empreendimentos só empregam a devida importância da manutenção, quando o problema já é existente. Esta demora em iniciar a manutenção torna os reparos mais trabalhosos e onerosos.

Além de promover a valorização do bem no mercado imobiliário, a manutenção de resguardo vai acarretar em um aumento da vida útil da edificação, melhoria no desempenho de equipamentos e instalações em geral, além de garantir a segurança, o conforto e a economia para o proprietário e para todos os usuários do edifício (VILLANUEVA, 2015). Nessa perpectiva conceitual, Araujo e Sales (2020) afirmam que a manutenção busca maximizar o desempenho quanto à segurança e habitabilidade dos edifícios e minimizar os custos dos serviços e as intervenções a serem efetuadas no mesmo.

Sacchi (2016) aborda em seu trabalho sobre Desempenho Estrutural e Manifestações Patológicas em Estruturas Metálicas, que para se evitar danos maiores nas estruturas metálicas, a implantação de manutenções preventivas associadas às manutenções corretivas devem ser executadas frequentemente, por profissionais com experiência neste tipo de avaliação e inspeção, utilizando os ensaios não destrutivos como uma ferramenta de grande importância, sendo possível avaliar a integridade e o atual estado de uso das edificações em estruturas metálicas.

Partindo do presuposto de implantação do LSF na cidade de Juazeiro do Norte, especificamente em relação à questão financeira, um dos principais obstáculos constatados nas construções em LSF nos locais de estudo foram os materiais estruturais, sobretudo os perfis de aço galvanizado, que vêm dos estados de São Paulo - SP e Paraná, devido não serem produzidos no estado do Ceará. Logo, esse fator torna o custo da obra mais caro e consequentemente influencia negativamente na escolha deste sistema construtivo para a região do Cariri. Todavia, alguns materiais são possíveis de encontrar na RMC, a exemplo das Placas OSB (Oriented Strand Board), Placas cimentícias, Gesso acartonado, Lã de Pet e Parafusos.

Foi identificado também que durante o revestimento interno da construção em LSF é utilizado Drywall, sendo que há em Juazeiro do Norte - CE uma empresa que fabrica esse material. 0 fato de existir apenas uma única empresa local que fabrica e vender esse material, está implicando no que se chama de 
monopólio e que acarreta o aumento de custo quando comparado com outras filiais da empresa existentes em outros estados do Brasil.

Outro entrave identificado na implantação do LSF é que na maioria das vezes os bancos financiadores das construções demoram a fazer o repasse do dinheiro aos clientes, por questões meramente burocráticas, o que acarreta atrasos no tempo de execução da edificação. Nesse sentido, muitos dos clientes que têm melhores condições financeiras e querem sua edificação construída de forma mais rápida, arcam com as despesas da obra para receberem posteriormente do agente financeiro.

Vale destacar que durante a execução da construção em LSF, as atividades não são subordinadas, pois enquanto os funcionários estão realizando a fundação de uma edificação, outros já estão montando os painéis, por exemplo. Em função disso, quanto mais rápido for feito o repasse financeiro aos clientes, mais rápida será a execução da obra evitando possíveis atrasos, pois esse entrave financeiro dificulta a compra dos materiais que vem de outros estados do País.

Um outro fator relevante identificado nas construções em LSF da área de estudo é que o desperdício de materiais chega em torno de $2 \%$ a $3 \%$ (FRANCISCO, 2019), o que representa um fator positivo em relação aos impactos ambientais negativos no ambiente, comparado às construções em alvenaria convencional. Portanto, o quesito sustentabilidade vem cada vez mais sendo valorizado para as edificações que utilizam esse sistema construtivo industrializado.

\section{Considerações Finais}

O objetivo deste trabalho foi realizar um levantamento das possíveis manifestações patológicas identificadas no sistema construtivo LSF na cidade de Juazeiro do Norte/CE. Através dos resultados, ficou notório que as edificações analisadas tinham pouco tempo de construção, mas que já apresentaram incidências patológicas.

Dentre os principais resultados, destaca-se que o sistema construtivo industrializado LSF possui muitas vantagens no mercado atual em alguns estados do país, e aos poucos vem sendo adotado também no estado do Ceará. No estudo em questão foi encontrado entraves na implantação do LSF na RMC, sobretudo acerca de alguns materiais necessários para a construção das edificações que vêm de outros estados, que consequentemente, acaba tornando o custo final da obra mais caro.

Nesta contribuição científica, ficou evidente também que as iniciativas como palestras em universidades/faculdades da região vem despertando o interesse dos alunos e profissionais da área que almejam ingressar ou se aprofundar nesse sistema, além de cursos e/ou treinamentos ofertados por profissionais que trabalham com o LSF, pois são imprescidíveis para o meio técnico uma vez que o sistema LSF exige, durante sua execução, mão de obra qualificada, sendo indispensável o conhecimento técnico e científico do sistema construtivo, tanto para quem está projetando quanto para a equipe que vai executar a construção. Ações como essas além de difundir o sistema construtivo na região, incentivam o uso do LSF pelos profissionais do mercado da construção civil.

Dessa maneira, o sistema construtivo industrializado LSF proporciona vantagens e benefícios para a construção civil, sendo o sistema mais avançado e seguro utilizado mundialmente. Por ser um sistema de construção seca, possibilita uma obra limpa, isenta de desperdícios e entulhos, entre outras características. Porém, como em qualquer outro método construtivo, o sistema possui desvantagens e barreiras, sendo que entre os principais impedimentos para sua aplicação no Brasil, destaca-se a ausência de informações necessárias, fator que aumenta o receio e a insegurança da população em adotar novos sistemas de construção.

Ademais, é necessário padronizar o uso de sistemas industrializados através de uma norma técnica para melhorar os padrões de eficiência, pois sem a norma efetiva do LSF é impossível estabelecer regras, critérios e características relacionadas ao desempenho, projeto e execução de todo o sistema. Dessa forma, com base na agregação de valores sustentáveis e benéficos, a aplicação desse sistema tem muito a contribuir no setor da construção civil, pois surge como contraponto aos sistemas construtivos convencionais que geram desperdícios, retrabalhos e são não sustentáveis.

Ainda que este trabalho vise despertar pesquisadores para uma nova forma de estudar as manifestações patológicas no sistema contrutivo LSF, algumas limitações foram vivenciadas em sua elaboração. A 
questão de existir poucas obras na área de estudo, e todas com poucos anos de construção, além dos entraves no registro fotográfico das edificações e das manifestações patológicas identificadas, por conta da não autorização por parte dos proprietários e a falta de registro fotográfico dos construtores durante a execução, ao mesmo tempo que configura uma limitação, engendra uma sugestão para futuras investigações: aumento das pesquisas sobre as manifestações patológicas no sistema construtivo LSF, pois através da elaboração de um banco de dados referente às estruturas é possível criar um sistema de gerenciamento com intuito de identificar todo seu processo construtivo, realizando análises e diagnósticos mais detalhados, a fim de planejar e priorizar as atividades de recuperação, restauração, dentre outras que garantam tomadas de decisões adequadas.

\section{Agradecimentos}

Os autores desejam agradecer a empresa A2 Engenharia e Arquitetura pela disponibilidade dos dados referentes as construções em Steel Frame na cidade de Juazeiro do Norte/CE.

\section{Referências Bibliográficas}

ARAUJO, L. E. F.; SALES, J. C. Utilização da Matriz GUT para avaliação das Manifestações Patológicas do Seminário Diocesano São José. In: MARINHO, J. L. A; MESQUITA, E. F. T. Patologia das Edificações: Manifestações nas Edificações e no Patrimônio Histórico. 1a ed. Editora Leud, São Paulo, 2020. P. 78-87.

CHAN, D. K.; FONTANIN, P. S. P. Análise do Uso do Sistema Light Steel Frame na Construção Civi. In: Workshop de Tecnologia de Processos e Sistemas Construtivos (TECSIC), 1., 2017, Campinas. Anais. [...]. Unicamp, Campinas, 2017. p. 1-8.

DEGANI, J. A. Construção Modular em Light Steel Frame: Comparativo com Construção em Alvenaria Convencional. 2017. 48f. Monografia (Engenharia Civil) - Universidade do Sul de Santa Catarina, Santa Catarina, 2017.

FRANCISCO, H. R. R. Depoimentos [jun. 2019]. [Entrevista cedida a] Lucas Menezes. Manifestações Patológicas no Sistema Construtivo Light Steel Frame. Juazeiro do Norte, Ceará, 2019.

HANDA, D. K. C. Identificação das Principais Manifestações Patológicas em Fachadas em Chapas Delgadas Estruturadas em Light Steel Framing - Estudos de caso. 2019. 206f. Dissertação (Mestrado em Engenharia Civil com área de concentração em construção) - Faculdade de Engenharia Civil, Arquitetura e Urbanismo, Universidade Estadual de Campinas, São Paulo, 2019.

IBGE - Instituto Brasileiro de Geografia e Estatística. Cidades e estados. 2020. Disponível: https://ibge.gov.br/. Acesso em: 10 jan. 2021.

IBGE/IPECE - Instituto Brasileiro de Geografia e Estatística/Instituto de Pesquisa e Estratégia Econômica do Ceará. Posição e extensão: Situação Geográfica. 2017. Disponível em: https://www.ipece.ce.gov.br/perfil-municipal-2017/. Acesso em: 7 jan. 2021.

MARINHO, J. L. A. Gerenciamento da Construção Civil: Reflexões sobre Sustentabilidade, Planejamento e Constrole de Obras. 1a ed. Curitiba: Editora Multideia, 2017.

MARINHO, J. L. A; MESQUITA, E. F. T. Patologia das edificações: Manifestações nas edificações e no patrimônio histórico. 1a ed. Editora Leud, São Paulo, 2020.

SCHAFIRSTEIN, L. M. M.; D’ÁVILA, C. A. C. Patologia e Reabilitação de Estruturas - Uma proposta Metodológica de Gestão e Controle. In: MARINHO, J. L. A; COELHO, F. C. A. Manifestações Patológicas e Reabilitação de Estruturas: Contribuições relevantes para Melhoria da Qualidade e Durabilidade das Estruturas. 1aㅡ ed. Editora Íthala, Curitiba, 2018. p.9-29.

SANTOS, M. J. B. O.; et al. Catalogação de Fissuras em Fachadas de Edifícios Residenciais em Brasília. In: MARINHO, J. L. A; COELHO, F. C. A. Manifestações Patológicas e Reabilitação de Estruturas: Contribuições relevantes para Melhoria da Qualidade e Durabilidade das Estruturas. $1^{\underline{a}}$ ed. Editora Íthala, Curitiba, 2018. 
SACCHI, C. C. Avaliação de Desempenho Estrutural e Manifestações Patológicas em Estruturas Metálicas. 2016. 138f. Dissertação (Mestrado em Estruturas e Construção Civil) - Universidade Federal de São Carlos, São Paulo, 2016.

TARGINO, D. L. L. et al. Análise estatística comparativa entre métodos de determinação da resistência à compressão de concretos por rompimento axial e estimativa ultrassônica. In: MARINHO, J. L. A; MESQUITA, E. F. T. Patologia das Edificações: Manifestações nas Edificações e no Patrimônio Histórico. $1^{\mathrm{a}}$ ed. Editora Leud, São Paulo, 2020. P. 66-77.

TEIXEIRA.; L.; A.; S.; SIMPLICIO.; M.; C.; A. A Modernização da Construção Civil Através do Uso do Steel Frame. Boletim do Gerenciamento, [S.l.], v. 2, n. 2, nov. 2018. ISSN 2595-6531.

VILlanUEVA, M. M. A Importância da Manutenção Preventiva para o Bom Desempenho da Edificação. 2015. 173f. Monografia (Bacharelado em Engenharia Civil) - Universidade Federal do Rio de Janeiro, Rio de Janeiro, 2015.

ZUEHL, M. E. Análise das Manifestações Patológicas em Estruturas de Aço - Light Steel Frame. 2019. 88f. Monografia (Graduação em Engenharia Civil) - Universidade de Santa Cruz do Sul, Rio Grande do Sul, 2019. 